\title{
Peningkatan Produktivitas Petani Kopi Melalui Sekolah Lapang Kopi dan Workshop Packing Process Berbasis Pemberdayaan Masyarakat
}

\author{
Riski Nur Istiqomah Dinnullah ${ }^{1}$, Novta Dany'el Irawan², Shafiq Nurdin³, \\ Djoko Adi Susilo ${ }^{4}$ \\ Universitas Kanjuruhan Malang, Jl. S. Supriyadi 48 Malang ${ }^{1,4}$ \\ Politeknik Unisma Malang, Jl. M.T. Haryono 193 Malang 2,3 \\ Email: ky2_zahra@unikama.ac.id ${ }^{1 *}$
}

(Diajukan: 05 Mei 2021, Direvisi: 31 Mei 2021, Diterima: 03 September 2021)

\begin{abstract}
ABSTRAK
Kopi merupakan salah satu komoditas unggul hasil pertanian di Desa Ngadirejo Kecamatan Jabung Kabupaten Malang. Namun, kondisi yang ada saat ini, banyak dari petani lebih senang menjual hasil kopi basah mereka daripada mengolahnya menjadi kopi bubuk dikarenakan minimnya pengetahuan mereka dalam proses pengolahan kopi. Mitra pada pengabdian ini adalah salah satu kelompok petani kopi di Desa Ngadirejo dengan ketua kelompoknya adalah Bapak Suranto yang juga memiliki usaha kopi bubuk. Permasalahan yang terjadi pada mitra adalah minimumnya pengetahuan kelompok tani ini dalam pengemasan produk kopi yang dihasilkannya. Hingga saat ini, proses pengemasan kopi tersebut hanya dibungkus dengan keresek putih dimana takarannya disesuaikan pemesanan kopi oleh pelanggan. Selain itu, mitra juga belum mengetahui bagaimana proses perawatan tanaman kopi yang baik setelah panen. Oleh karena itu, tujuan diadakannya kegiatan pengabdian ini adalah (1) memberikan sekolah lapangan terkait penanganan tanaman kopi setelah panen; dan (2) melakukan pelatihan dan pendampingan mengenai packing process produk kepada petani kopi yang juga sebagai pemilik usaha kopi tersebut. Dalam pengabdian ini, metode yang digunakan adalah transfer ilmu pengetahuan kepada para petani kopi melalui sekolah lapangan kopi terkait cara perawatan tanaman serta cara mendesain merk dagang maupun packing process kepada pemilik usaha. Setelah kegiatan pengabdian dilaksanakan, dampak yang terjadi adalah (1) mitra telah memiliki pengetahuan dan kemampuan dalam merawat tanaman kopi, (2) mitra telah mengetahui cara membuat desain merk sederhana dan mengemas produknya sendiri dengan baik. Melalui kegiatan ini diharapkan mampu meningkatkan nilai jual produk kopi mitra serta memperluas area pemasarannya.
\end{abstract}

Kata kunci: Kopi, Sekolah Lapangan, Packing Process, Desain Merk

\section{ABSTRACT}

Coffee is one of the superior agricultural commodities in Ngadirejo Village, Jabung District, Malang Regency. However, the current conditions, many of the farmers prefer to sell their wet coffee rather than processing it into coffee grounds because of their lack of knowledge in the coffee processing process. The partner in this service is one of the coffee farmer groups in Ngadirejo Village with the group leader being Mr. Suranto who also owns a ground coffee business. The problem here is (1) the minimum knowledge of this farmer group in packaging the coffee products they produce; and (2) Partners also do not know how to properly care for coffee plants after harvest. The purpose of holding this service is (1) to provide fields related to handling plants after harvest; and (2) providing training and assistance regarding the product packaging process to coffee farmers who are also the owners of the coffee business. In this service, the method used is to transfer knowledge to coffee farmers through coffee field schools regarding how to care for plants and how to design trademarks and packaging processes to business owners. After the activity was carried out, the impacts that occurred were (1) partners had the knowledge and ability to care for coffee plants, (2) partners knew how to make brand designs and produce their own products well.

Keywords: Coffee, Field School, Packing Process, Brand Design 


\section{PENDAHULUAN}

Kopi merupakan salah satu hasil komoditi perkebunan yang memiliki nilai ekonomis yang cukup tinggi di antara tanaman perkebunan lainnya (Azizah, Sutamihardja, dan Wijaya, 2019). Kopi tidak hanya berperan penting sebagai sumber devisa melainkan juga merupakan sumber penghasilan bagi tidak kurang dari satu setengah juta jiwa petani kopi di Indonesia (Budihardjo dan Fahmi, 2020). Berdasarkan data dari Badan Pusat Statistik diketahui bahwa produksi kopi di Indonesia pada tahun 2020 adalah 753,9 ribu ton (BPS, 2020).

Desa Ngadirejo yang berada di Kecamatan Jabung Kabupaten Malang, merupakan daerah pegunungan dan perbukitan yang termasuk dalam kategori dataran tinggi dengan ketinggian 800-1200 mdpl. Luas wilayah desa mencapai 1016,25 Ha dengan jumlah penduduk sebanyak 2.322 jiwa pada akhir tahun 2018. Berdasarkan hasil wawancara dengan Perangkat Desa Ngadirejo, hampir semua penduduk desa memiliki lahan perkebunan kopi yang cukup luas sehingga mata pencaharian utama masyarakat desa tersebut adalah sebagai petani kopi. Pada tahun 2020, total produksi kopi yang dihasilkan adalah 100 ton dari jenis Kopi Robusta.

Mitra pada pengabdian ini adalah salah satu kelompok petani kopi di Desa Ngadirejo dengan ketua kelompoknya adalah Bapak Suranto yang juga memiliki usaha kopi bubuk. Kelompok paguyuban petani ini memiliki \pm 25 anggota. Setiap panen dalam setahun, produksi yang dihasilkan adalah sekitar 35 ton kopi basah dengan harga jualnya adalah Rp. 6.500/kg. Selain menjual kopi basah, beberapa petani juga menjual kopi bubuk dengan rata-rata harga jualnya adalah Rp. 18.000/kg. Area pemasaran kopi ini adalah wilayah Malang Raya dan sekitarnya.

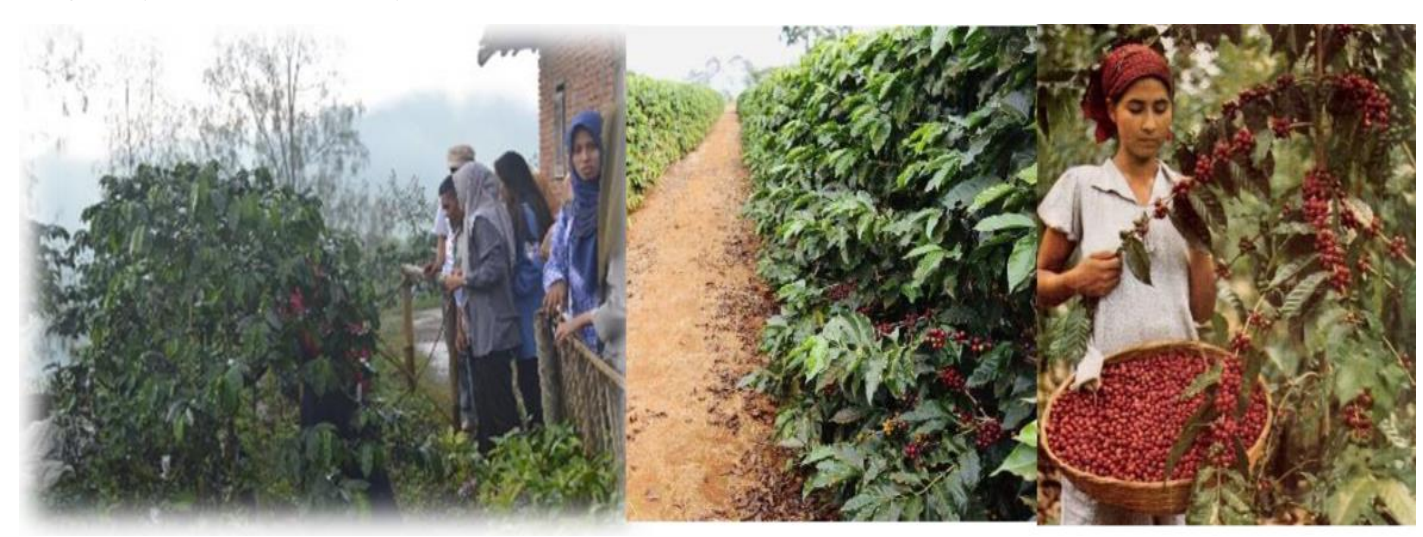

Gambar 1. Petani Kopi Desa Ngadirejo 
Berdasarkan hasil observasi dan wawancara dengan mitra, permasalahan pertama yang dialami adalah bahwa para petani kopi masih belum memiliki pengetahuan bagaimana perawatan tanaman kopi pasca panen. Beberapa petani belum mengetahui teknik penting dalam budidaya kopi terutama pada proses pemangkasannya. Seringkali petani memangkas tanaman kopi tersebut secara asal-asalan tanpa mengetahui cabang mana yang seharusnya dipotong. Sementara, permasalahan yang kedua adalah proses pengemasan produk kopi yang tidak rapi. Saat ini, pengemasan hanya dibungkus dengan keresek putih tanpa menggunakan takaran baku dan disesuaikan dengan permintaan pemesan saja. Kurangnya pengetahuan dalam proses pengemasan ini menyebabkan rendahnya harga jual kopi. Hal ini tentunya mempengaruhi produktivitas dari petani kopi mengingat biaya penanaman dan perawatan kopi cukup menguras biaya. Selain itu, produk kopi mitra masih belum memiliki merk dagang, sehingga masyarakat luas banyak yang belum mengenal kopi Ngadirejo milik mitra. Dengan demikian, adanya pengabdian ini bertujuan untuk memberikan sekolah lapangan terkait perawatan tanaman kopi serta pelatihan dan pendampingan dalam membuat desain merk sederhana serta packing process produk kopi yang baik dan menarik. Diharapkan kedepannya, petani kopi mampu menghasilkan kopi secara lebih optimal dan meningkatkan nilai jual produk kopinya sehingga dapat meningkatkan kesejahteraan bagi petani kopi.

\section{METODE}

Metode kegiatan pengabdian ini adalah dengan melakukan Focus Group Discussion (FGD) yaitu melakukan diskusi bersama antara tim pengabdi dengan ketua dan beberapa anggota petani kopi. FGD ini digunakan untuk mengidentifikasi masalah mitra, menentukan prioritas masalah dan memberikan solusi yang tepat bagi mitra. Pelaksanaan kegiatan ini meliputi penyuluhan, workshop dan pendampingan serta evaluasi untuk melihat efektivitas program pengabdian masyarakat ini di lapangan. Selanjutnya, rencana kegiatan pengabdian ini pada gambar 2 . 


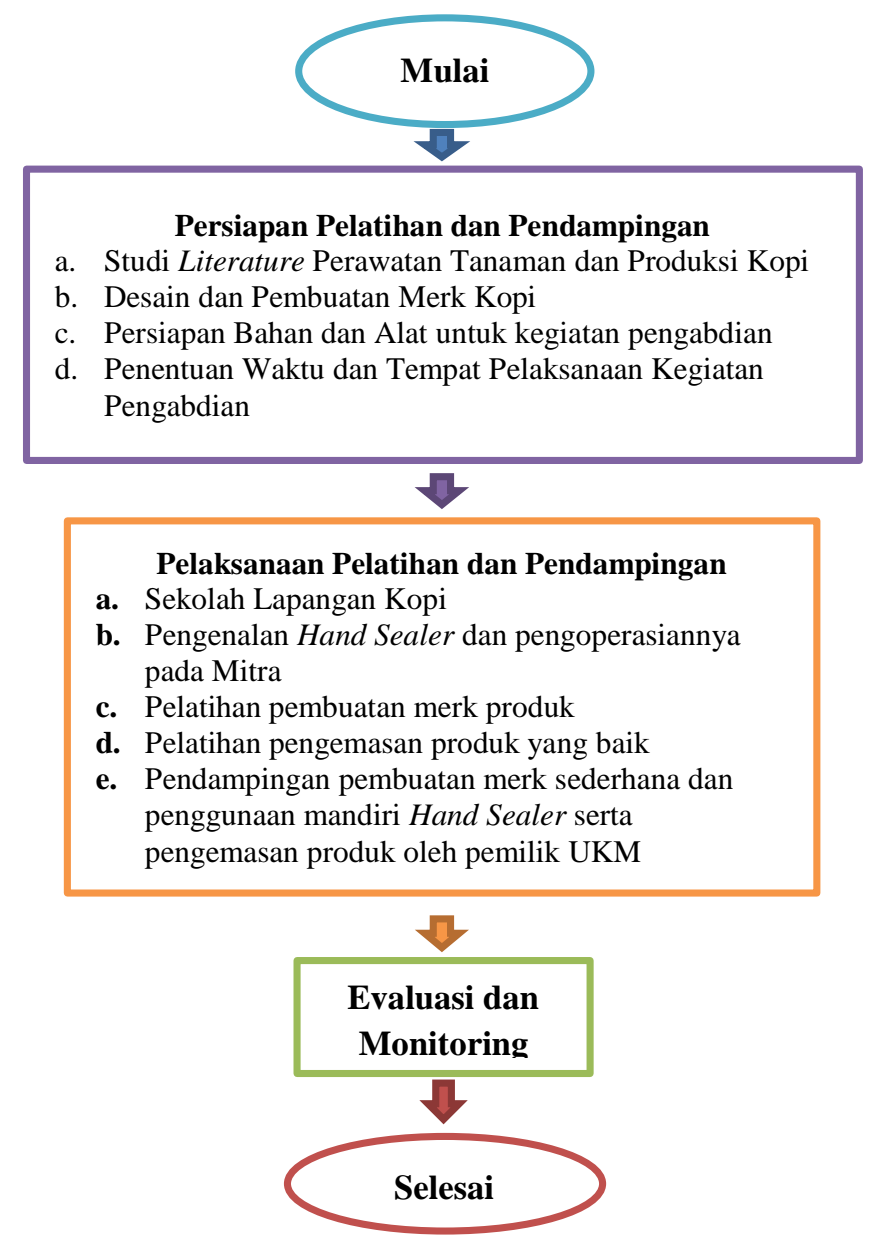

Gambar 2. Diagram Alir Pelaksanaan Kegiatan

Persiapan pelatihan dan pendampingan ini diawali dengan studi literature terkait perawatan tanaman kopi serta proses produksi kopi bubuk. Dilanjutkan dengan proses untuk kegiatan sekolah lapang seperti bahan workshop dan modul terkait perawatan tanaman kopi. Selanjutnya, persiapan alat dan bahan untuk proses desain merk aseperti setting aplikasi mobile, kertas sticker, dan printer. Sementara untuk packing process alat dan bahan yang digunakan adalah hand sealer, plastik standing pouch, dan kopi bubuk.

Beberapa alat dan bahan lainnya seperti kopi, sendok, baskom, timbangan digital seduah disepakati bersama akan disiapkan oleh mitra. Pada kegiatan pengabdian ini, hal yang sangat penting adalah menentukan waktu dan tempat pelaksanaan pelatihan bersama mitra dan telah ditentukan bahwa kegiatan pengabdian akan dilaksanakan 24 Mei - 18 Juni 2021.

Dalam kegiatan ini, seluruhnya melibatkan partisipasi dari mitra secara langsung. Kegiatan ini dimaksudkan untuk menanamkan rasa kepemilikan mitra dalam kegiatan ini, sehingga dengan model partisipasi penuh dari mitra akan mensukseskan kegiatan 
pengabdian masyarakat ini serta dapat membantu dalam pemasaran produk dalam meningkatkan pendapatan pelaku usaha tersebut.

Kegiatan terakhir adalah tahap monitoring dan evaluasi yang dilakukan agar proses keberlanjutan oleh mitra yang tentunya masih membutuhkan pembimbingan dalam proses pelaksanaan program. Tahap ini akan dilaksanakan bersama mitra setiap tiga bulan sekali setelah dilaksanakannya program. Maka dari itu, tujuan dari tahap ini antara lain:

a. Melihat perkembangan program yang telah dilaksanakan.

b. Mengetahui kendala yang ada dalam proses pelaksanaan program.

c. Mencari solusi terhadap masalah yang ada.

\section{HASIL, PEMBAHASAN, DAN DAMPAK}

Jadwal pelaksanaan kegiatan pengabdian masyarakat serta narasumber untuk setiap kegiatan ini dapat dilihat pada tabel 1 .

Tabel 1. Pelaksanaan Kegiatan Pengabdian

\begin{tabular}{clcl}
\hline No & \multicolumn{1}{c}{ Kegiatan } & Pelaksanaan & \multicolumn{1}{c}{ Pemateri } \\
\hline 1 & Sekolah Lapangan I & 26 Mei 2021 & Sertu Heri Purnomo \\
\hline 2 & Sekolah Lapangan II & 29 Mei 2021 & Sertu Heri Purnomo \\
\hline 3 & $\begin{array}{l}\text { Workshop Pengenalan dan } \\
\text { pengoperasian Hand sealer }\end{array}$ & 31 Mei 2021 & Riski Nur I. D., M.Si. \\
\hline 4 & Workshop Desain Merk Produk & 7 Juni 2021 & Riski Nur I. D., M.Si. \\
\hline 5 & $\begin{array}{l}\text { Workshop Manajemen } \\
\text { Pengemasan }\end{array}$ & 9 Juni 2021 & $\begin{array}{l}\text { Drs. Djoko Adi Susilo, } \\
\text { M.Pd. }\end{array}$ \\
\hline 6 & $\begin{array}{l}\text { Pelatihan dan pendampingan } \\
\text { pengoperasi mesin secara } \\
\text { mandiri oleh pemilik usaha }\end{array}$ & 14 Juni 2021 & $\begin{array}{l}\text { Drs. Djoko Adi Susilo, } \\
\text { M.Pd. }\end{array}$ \\
\hline 7 & $\begin{array}{l}\text { Evaluasi Kegiatan antara tim } \\
\text { bersama mitra }\end{array}$ & 16 Juni 2021 & \\
\hline & & &
\end{tabular}

Kegiatan Sekolah Lapang I dan II diberikan oleh Sertu Heri Purnomo yang juga merupakan Babinsa Desa Ngadirejo. Untuk Kegiatan Sekolah Lapang I dilakukan di kediaman Bapak Suranto dan Kegiatan Sekolah Lapang II dilakukan dengan praktek secara langsung perawatan kopi serta proses pemangkasan tanaman kopi yang baik di kebun kopi Bapak Suranto. Kegiatan ini dikuti oleh para petani Desa Ngadirejo sekitar kurang lebih 25 orang. Pada kegiatan tersebut, terlihat bahwa peserta sangat bersemangat dalam berdiskusi bersama serta para petani tersebut mengungkapkan bahwa kegiatan yang 
dilakukan secara langsung dilapangan membuat para petani dapat mempraktikkan secara langsung apa yang sudah disampaikan oleh pemateri.
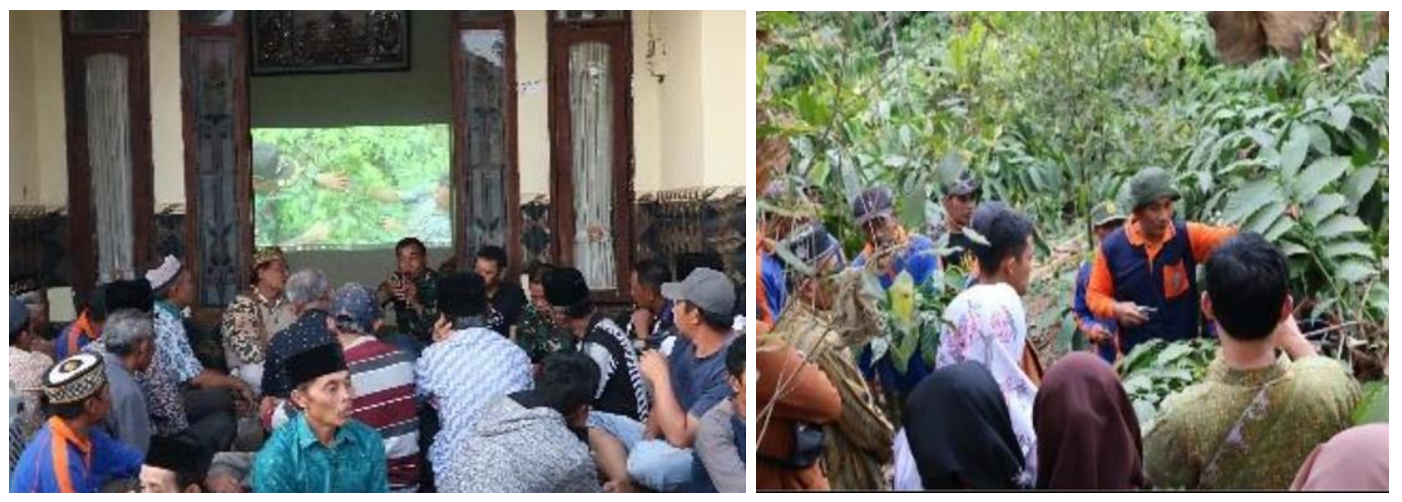

Gambar 3. Sekolah Lapang I dan II

Sementara, kegiatan workshop pelatihan dan pendampingan diberikan oleh tim pengabdi Unikama. Pada kegiatan ini peralatan yang digunakan yaitu hand sealer dan plastik kemas stand pouch ukuran $500 \mathrm{~kg}$ untuk kemasan kopi dan kertas sticker ukuran A4 untuk merk produk.

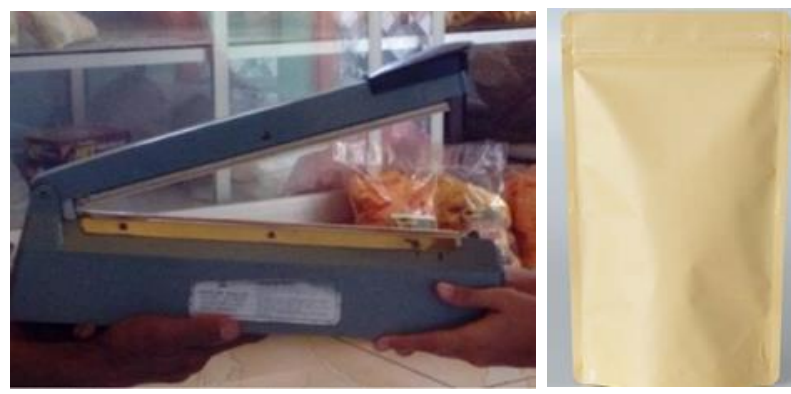

Gambar 4. Hand Selaer dan Kemasan Stand Pouch

Spesifikasi Hand Selaer diberikan sebagai berikut
a. Tipe
: Side Cutter Model.
b. Model
: PCS200C.
c. Impulse Power : 300W.
d. Seal Length $\quad: 200 \mathrm{~mm}$.
e. Seal Width $\quad: 2 \mathrm{~mm}$.
f. Machine Weight $: 2.7 \mathrm{~kg}$. 

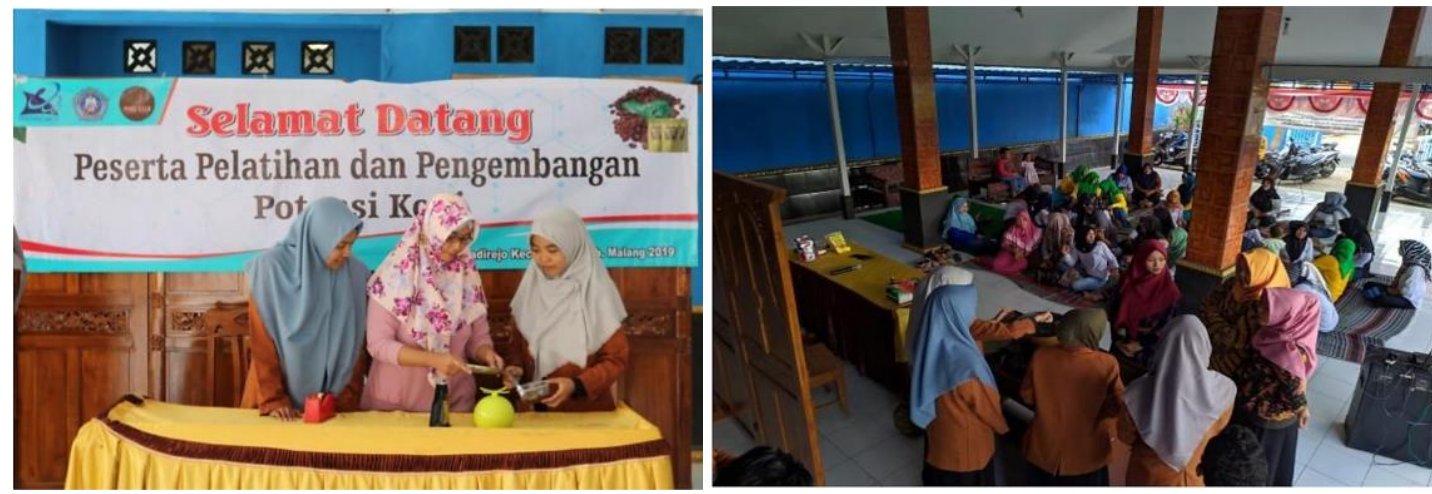

Gambar 5. Kegiatan Pelatihan dan Pendampingan bersama Istri petani Desa Ngadirejo

Kegiatan pelatihan dan pendampingan ini diikuti oleh sekitar kurang lebih 20 orang yang merupakan istri dari petani kopi Desa Ngadirejo. Di kegiatan ini, para peserta diminta oleh Tim pengabdi UNIKAMA untuk mencoba secara langsung mengoperasikan hand sealer serta memberikan workshop terkait langkah-langkah perawatan dan perbaikan dasar hand sealer. Penggunaan hand sealer dalam proses pengemasan dirasa sangat penting karena hal tersebut mampu meningkatkan kualitas produk (Suryanti, dan Mediaswati, 2017). Sesuai dengan pengabdian yang telah dilakukan Dinnullah, Nurdin, dan Sumadji (2018) bahwa produk yang dapat terkemas dengan baik dapat menghindari terjadinya kebocoran dan kontaminasi udara dari luar.

Selain itu, pada kegiatan ini peserta juga dibimbing untuk dapat membuat desain sederhana merk dagang produknya secara mobile. Dalam pembuatan nama pada merk ini, tim menyampaikan kepada peserta agar nama merk tersebut dapat merepresentasikan produknya. Hal ini sejalan dengan pengabdian Fitriani dkk., (2020) bahwa pembuatan merk yang baik harus dapat memberikan informasi kepada konsumen terkait dengan produk yang dihasilkannya. Dalam pembuatan merk ini tim menyarankan agar mitra dapat menggunakan foto produknya yang eye catching sehingga dapat menarik minat pelanggan tersebut.

Sementara itu, dampak setelah dilaksanakan kegiatan pengabdian ini adalah (i) Dengan diadakannya sekolah lapang kopi, pengetahuan petani kopi tentang perawatan tanaman kopi menjadi bertambah. (ii) Terjadi peningkatan pengetahuan dan keterampilan petani kopi yang memiliki usaha penjualan kopi bubuk dalam membuat merk produknya. (iii) Pengusaha kopi bubuk tersebut sudah mampu mengemas produknya sendiri dengan baik. 


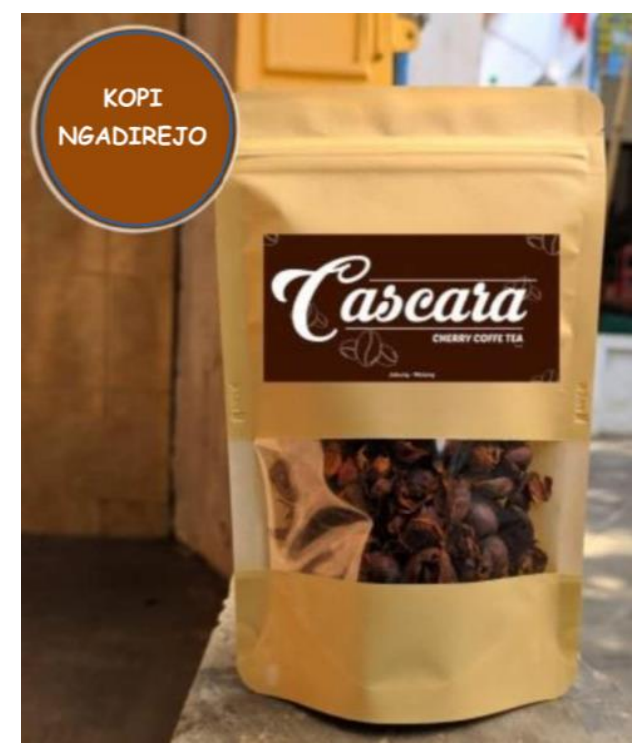

Gambar 6. Produk Kopi Desa Ngadirejo

Setelah kegiatan ini dilaksanakan, tim pengabdi melakukan evaluasi bersama dengan ketua kelompok tani kopi yaitu Bapak Suranto. Hasil diskusi tersebut dapat diketahui bahwa masyarakat petani kopi mendapatkan banyak ilmu pengetahuan lebih mendalam terkait perawatan tanaman kopi terutama teknik pemangkasan. Para petani tersebut telah memahami akan pentingnya teknik yang dilakukan dalam proses pemangkasan. Hal tersebut sesuai dengan Sianturi dan Wachjar (2016), bahwa agar mendapatkan produksi yang optimal maka proses pemangkasan harus dilaksanakan dengan baik dan tepat. Hal ini juga akan sangat memudahkan petani pada saat proses pemanenan buah kopi.

Selain itu, dalam kegiatan evaluasi ini, tim juga mengetahui beberapa permasalahan yang belum terselesaikan, yaitu: (i) Masyarakat kurang memahami cara mengolah kopi pasca panen. Banyak dari petani kopi yang menjemur buah kopi langsung di atas aspal. (ii) Masyarakat belum dapat memasarkan produk kopi mereka melalui media online. (iii) Masyarakat belum mengetahui cara mengolah kopi menjadi produk olahan kopi lainnya. Beberapa kendala tersebut telah menjadi poin penting bagi tim pengabdi dan diagendakan menjadi kegiatan pengabdian lanjutan.

\section{SIMPULAN}

Kegiatan sekolah lapang kopi serta pelatihan dan pendampingan Packing Process pada pengabdian yang dilaksanakan ini mendapatkan antusias yang tinggi dari petani kopi Desa Ngadirejo. Selain itu, mitra juga berpartisipasi penuh dalam kegiatan mulai dari keikutsertaan mitra dalam mempersiapkan alat dan bahan hingga penentuan jadwal dan tempat pelaksanaan kegiatan ini. Berdasarkan wawancara dengan ketua paguyuban pada 
saat kegiatan evaluasi dapat diketahui bahwa (i) Masyarakat telah mampu memahami dan melakukan perawatan tanaman kopi dengan baik. (i) Masyarakat yang memiliki usaha produksi kopi bubuk telah mampu membuat merk dagang sendiri serta mengemas produk dengan baik dan menarik. Untuk keberlanjutan program pengabdian ini maka kegiatan pengabdian selanjutnya akan diberikan sebagai bentuk kerjasama antara mitra dengan universitas dan tim pengabdi.

\section{DAFTAR PUSTAKA}

Azizah, M., Sutamihardja, R. T. M., dan Wijaya, N. (2019). Karakteristik Kopi Bubuk Arabika (Coffea Arabica L) Terfermentasi Saccharomyces cerevisiae. Jurnal Sains Natural Universitas Nusa Bangsa, 9(2), 37-46. doi: 10.31938/jsn.v9i1.173

Badan Pusat Statistik. (2020). Statistik Indonesia. Jakarta: BPS-Statistics Indonesia.

Budihardjo, K. dan Fahmi, W. M. (2020). Strategi Peningkatan Produksi Kopi Robusta (Coffea L.) Di Desa Pentingsari, Kecamatan Cangkringan, Kabupaten Sleman, Daerah Istimewa Yogyakarta. Jurnal Ilmiah Mahasiswa AGROINFO GALUH. 7(2), 373-379. doi: $10.25157 /$ jimag.v7i2.3338

Dinnullah, R. N. I., Nurdin, S., dan Sumadji. (2018). Packing Process Dalam Pelatihan Kemandirian Ukm Kerupuk Bawang Sebagai Upaya Peningkatan Pemasaran Produk. J-ADIMAS (Jurnal Pengabdian Kepada Masyarakat), 6(2), 57-62. doi:

Fitriani, E., Fatimah, S., Mardiah, D., Selinaswati, S., Hidayat, M., \& Amelia, L. (2020). Pengemasan (Packaging) Rakik Bada Lado Hijau Upaya Peningkatan Pemasaran dan Pelestarian Kuliner Minangkabau. Abdi: Jurnal Pengabdian Dan Pemberdayaan Masyarakat, 2(2), 130-135. doi: 10.24036/abdi.v2i2.59.

Sianturi, V. F. dan Wachjar, A. (2016). Pengelolaan Pemangkasan Tanaman Kopi Arabika (Coffea Arabica L.) di Kebun Blawan, Bondowoso, Jawa Timur. Bul. Agrohorti, 4(3), 266-275.

Suryanti, F., \& Mediaswati, K. A. (2017). Usaha Kecil dan Menengah Keripik Tempe di Kecamatan Blimbing Kota Malang Untuk Peningkatkan Pendapatan Usaha. JAST: Jurnal Aplikasi Sains dan Teknologi, 1(1). doi: 10.33366/jast.v1i1.717 